
\title{
Barriers Affecting the Diffusion of Business-to- Consumer Online Retailing Acceptance in Kingdom of Saudi Arabia
}

\author{
Anisur Rehman* \\ Department of Management and Information System, College of Business Administration, University of Hail, Hail, \\ Saudi Arabia; anisur.rehman11@gmail.com
}

\begin{abstract}
Objectives: The study is to identify the impediments affecting business-to-consumer (B2C) online shopping in the Kingdom of Saudi Arabia. This research concentrates on the demographic survey of the buyers and their influence on buyer sensitivity to internet purchasing obstructions. Methods/analysis: This study is a descriptive survey design. Quantitative data is collected using an online questionnaire. The respondents were asked questions about their demographic profile and their observed impediments to internet purchasing. The sample size is 240 respondents who had engaged in online shopping only once or never engaged in online shopping. Frequency counts, mean score, ranking and chi-square test were the statistical techniques deployed to test the hypotheses using SPSS statistical software. Findings: The most important observed impediments to internet purchasing were identified as security and privacy risks in online shopping, the English language barrier, trusting tangible products, not using a credit card and the issue of distrust and credibility. It was found that the barrier of security and privacy risks in online shopping is independent of the educational status of interviewees. The hurdle of believing tangible goods does not depend on the age of interviewees. Moreover, the barrier of distrust and credibility is dependent on the online shopping experience of customers. Novelty/improvement: This study can help online retailers to understand the barriers affecting consumers' online buying behavior, which can help retailers to create their selling approach to change prospective buyers into real buyers.
\end{abstract}

Keywords: E-Commerce Barriers, Online Shopping Behavior, Security Risk, Language Barrier, Online Trust

\section{Introduction}

In ancient days, consumers visited the market personally for purchasing their daily needs products. There are no substantial variations between the traditional shops before and stores today. The business world has experienced a big change in different areas such as market place, product types, services, the type of operations and processes. But this growth has been defied by the prominence of webshops where buyers have the freedom to make purchases by sitting in their rooms. The current situation confirms that remote space is now an insignificant matter for purchasers to shop and negotiate on products they like to buy. 1
The electronic trade business in Saudi Arabia has seen substantial progress in recent times. B2C internet trade expenditure was more than SAR 29.7 billion in 2016. The main drivers that are causing this switch toward internet shopping in Saudi Arabia are the high number of youth, more internet and smart-phone usage, easy settlement options and favorable policies.

The present online payment infrastructure in Saudi Arabia is witnessing changes as a result of the latest digital payment means such as PayPal and Cash $U$ which provide easy and secure payment options to buyers. $\stackrel{2}{2}$

The usual internet buyer in Saudi Arabia purchases over the internet at a minimum one time in three months and expends an average of about SAR 4,000 on

${ }^{*}$ Author for correspondence 
internet buying in a year. This is fuelled by the ease of home deliveries, the timesaving benefits of e-commerce, attractive Internet offers, and the wide range of products. Even then, Saudi shoppers' inclination to make purchases through traditional channels remains high. .2

Figure 1 shows the UNCTAD worldwide study conducted in 2017 to discern and gauge the preparedness of countries towards internet shopping. The countries were evaluated on the basis of four standards to calculate the final value. The four standards are web consumption, protected servers per 1 million citizens, infiltration of banks, and trustworthiness of postal system which are vital indicators for online market growth inside a country. $\underline{2}$ The rank of Saudi Arabia was 46th from a list of 144 countries, and the index score was 69 . It is at the same level as Italy and Russia and at a higher level than India and China. $\underline{2}$

\section{Literature Survey}

A large number of researches have been undertaken worldwide to better comprehend concerns and determinants to acceptance of online buying. Online buying acceptance has been researched for both internet technology and buyer behavior. $\underline{3}^{-}$

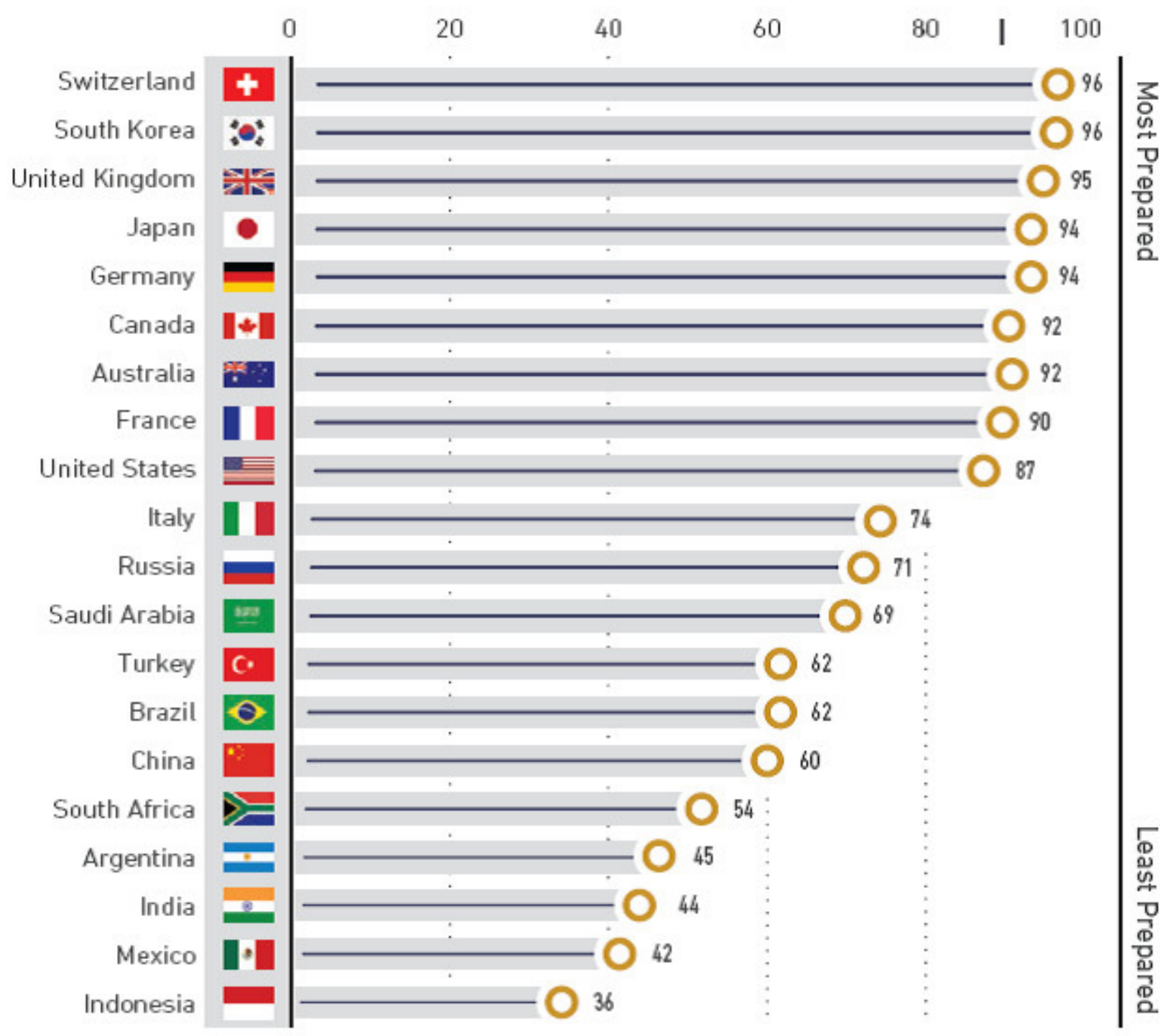

Figure 1. Comparison of UNCTAD e-commerce readiness score (2017). Source: UNCTAD B2C E-commerce Index, United Nations Conference on Trade and Development (UNCTAD), 2017. 


\subsection{E-Commerce Constraints}

Online shopping researchers have identified the buyer's faith as an observed threat and a hurdle to online shopping acceptance. Buyers having earlier web interaction have a favorable approach towards online purchases and have more confidence in it. .3

A cross-country comparison survey including USA, Germany, France, Denmark, Brazil, Mexico, Japan, China and Singapore explored the world-wide, environmental and policy factors of e-commerce. It concluded that buyer's requirements to shop on the internet, shopper buying capacity, commerce online preparedness, powerful ICT foundation, and government support work as facilitators for B2C internet shopping. In contrast, language, settlement alternatives, various buying avenues, buyer mistrust, buying avenue fondness, online product details, and disparity in society levels act as impediments to $\mathrm{B} 2 \mathrm{C}$ online purchase. ${ }^{3} \mathrm{~A}$ study on internet marketing in India revealed consumer perceptions of the time duration, buying convenience, trustworthiness, prestige, the convenience of comparison, the peril of monetary transactions and prompt supply show substantial connections with their internet purchase plan. $\underline{4}$

Impediments preventing online buying acceptance in developing countries was studied by OECD. It was found that infrastructure hurdles like technology cost, safety and protection concerns, settlement methods, unsatisfactory delivery, post-sale customer support, and intangibility of internet buying environment were the highly identified determinants. $\underline{3}$

SEC report on transboundary internet purchase across the European States found that language, cultural obstacles, settlement options, distribution and postsales service are the significant impeding determinants. 3 Study exhibits that the chief cause consumers have not purchased on the web is the basic mistrust between most traders and buyers on the internet today. .5

Privacy was ranked as the top issue (46.9\%) in a recent study whereas security ranked as the lowest concern to buyers $(1.1 \%)$ in e-commerce. Normally buyers purchase from internet pages they have trust on but they are concerned with credit card scam, unsolicited use of their private information for other tasks. In most instances, product risk is cited as the reason for not buying on the web. Product risk means how buyers see online merchandise and if it meets their hope or not. Product risk rises if the good is complicated technologically, connected with greater self-esteem requirements is expensive, or its tangibility is important. $\underline{5}$

Many researchers consider online purchasing as an innovation. Innovation has a serious drawback, i.e. the resistance it faces from purchasers. Functional and psychological barriers are the main types of innovation barriers. The buyer's perception of significant changes if newness is adapted leads to functional barriers. They include three impediments - Usage hurdle, Value hurdle and Risk hurdle. Psychological barriers appear when buyers feel a clash between innovation and their earlier views. The categories of psychological impediments include tradition hurdle and image hurdle. $\underline{5}$ Some instances of internet purchasing image hurdles are a complex procedure, time-consuming, poor distribution system and returning undesirable products. $\underline{5}$

\subsection{E-Commerce in Saudi Arabia}

Sacha Consulting Group studied the impediments that influence the surge of electronic trade in Saudi Arabia3. The main impediments were found to be fondness of direct one-to-one trade deals, hesitation to engage in online purchasing, less payment options, language, and reluctance to change, risk-avoiding behavior, poor customer support and after-sale service, internet privacy, and postal system. Old mailing service infrastructure, lack of government rules and web payment procedure were recognized as the most noticed impediments in a research on internet purchase acceptance in Saudi Arabia. $\underline{6}$ A research on feeling of Saudi internet buyers found that the impediments to internet buying are bad sales services experience, risk in monetary transactions, fear of identity theft and password hacking, and lack clearly defined service policy. ${ }^{7}$

Earlier, mail in Saudi Arabia was delivered to Post Boxes because of uncertain location details. The old postal system was recognized as an impediment to online purchase acceptance in Saudi Arabia. $\underline{3}$ Wasel service was initiated by the government in 2005 under which home shipment of mail was commenced by Saudi postal services. Smart mailboxes were used for mail delivery. These boxes used satellite links and employed GPS technology to find the exact location of the consumer.

The assessment of the aforementioned researches pointed out that despite the fact that there is a vast literature regarding web consumption, internet purchasing, and elements affecting web acceptance, not 
many had concentrated on Saudi buyers. This survey will seek to address the shortcomings regarding this domain of research. $\frac{3}{2}$

Traders in Saudi Arabia are gradually implementing the internet buying vision. The knowledge of internet buying advantages was found to be less. A study identified internet access, e-commerce facilities, e-shopping knowledge and publicity as critical issues for the success of internet shopping in Saudi Arabia. $\underline{5}$

Some latest studies examined internet shopping expansion,,$\underline{8} \underline{\underline{9}}$ online services acceptance, $\underline{10}$ and cyberspace espousal. $\underline{11}, \underline{12}$

Elements that prevent traders from accepting the webspace as a buying channel medium were studied. The most notable hurdles from traders' viewpoints are inadequate ICT framework, weak electronic trade laws, postal system, and limited experience. 13,14 The acceptance of internet shopping in Saudi Arabia faced a serious roadblock due to inadequate postal system. $\underline{15}$

\section{Research Methodology}

The study is descriptive research. A web-based survey has been employed to gather quantitative evidence. The introductory section of the questionnaire asked respondents about their personal details like internet buying experience, gender, age, educational qualification and employment. The second section asked questions regarding the observed impediments to internet purchasing. The questionnaire employed a Likert scale rating.

Google Docs application was used to develop the questionnaire. The electronic questionnaire is distributed through e-mail and social media channels in Arabic and English language.

The main target sample for this study was respondents who had zero or very limited experience of online shopping. The difficulty was to identify such consumers. Therefore, a question was included in a questionnaire regarding the online shopping experience of respondents. Then, 715 consumers were identified through snowball sampling who was perceived to be having little knowledge of technology and the internet.

These respondents were given the questionnaire out of which, 418 replies were obtained. From these 418 responses, 143 respondents had engaged in online shopping only once and 97 respondents had never engaged in online shopping, making a total of 240 respondents. This set of 240 respondents was used to collect the data, and they were asked to proceed with answering the remaining questions. The remaining 178 respondents who were frequent online buyers were not included in this study and they were asked to refrain from answering the remaining questions. Frequency counts, mean score, ranking and chi-square test were the statistical techniques deployed to test the study hypotheses using SPSS statistical software.

\subsection{Objectives}

The objectives of this study are as follows:

1. To study the barriers influencing B2C online retailing in Saudi Arabia.

2. To survey the buyer's demography and its effect on the buyer's feelings regarding internet purchasing impediments.

\subsection{Hypothesis}

H01: The impediment of security and privacy risks in internet purchasing is independent of the education level of respondents.

H02: The barrier of trusting only tangible products is independent of the respondent's age.

H03: The hurdle of mistrust and trustworthiness is independent of the online shopping experience of buyers.

Sample Size: The survey was collected from 240 respondents from Hail, Qassim and Riyadh region.

\section{Data Analysis and Interpretation}

Tables 1-5 reveal the demography of the respondents like Internet buying experience, gender, age, educational qualification \& employment.

Table 1. Internet buying experience

\begin{tabular}{|l|c|c|}
\hline Experience & $\begin{array}{c}\text { No. of } \\
\text { respondents }\end{array}$ & Percentage \\
\hline Frequent online buyer & 178 & $42.6 \%$ \\
\hline $\begin{array}{l}\text { Engaged only once in online } \\
\text { shopping }\end{array}$ & $143^{\star}$ & $34.2 \%$ \\
\hline $\begin{array}{l}\text { Never engaged in online } \\
\text { shopping }\end{array}$ & $97^{\star}$ & $23.2 \%$ \\
\hline Total & 418 & $100 \%$ \\
\hline
\end{tabular}

* This is the sample used for data collection. 
Table 2. Gender of respondents

\begin{tabular}{|l|c|c|}
\hline Gender & No. of respondents & Percentage \\
\hline Male & 168 & $70 \%$ \\
\hline Female & 72 & $30 \%$ \\
\hline Total & 240 & $100 \%$ \\
\hline
\end{tabular}

Table 3. Age of respondents

\begin{tabular}{|l|c|c|}
\hline Particulars & No. of respondents & Percentage \\
\hline Less than 18 years & 26 & $10.8 \%$ \\
\hline $18-29$ years & 136 & $56.7 \%$ \\
\hline $30-39$ years & 60 & $25 \%$ \\
\hline 40 years or more & 18 & $7.5 \%$ \\
\hline Total & 240 & $100 \%$ \\
\hline
\end{tabular}

Table 4. Educational qualification

\begin{tabular}{|l|c|c|}
\hline Particulars & No. of respondents & Percentage \\
\hline Intermediate & 18 & $7.5 \%$ \\
\hline Under-graduate & 128 & $53.3 \%$ \\
\hline Graduate & 64 & $26.7 \%$ \\
\hline $\begin{array}{l}\text { Masters and } \\
\text { above }\end{array}$ & 30 & $12.5 \%$ \\
\hline Total & 240 & $100 \%$ \\
\hline
\end{tabular}

Table 5. Employment

\begin{tabular}{|l|c|c|}
\hline Particulars & No. of respondents & Percentage \\
\hline $\begin{array}{l}\text { Government } \\
\text { employee }\end{array}$ & 38 & $15.8 \%$ \\
\hline Private Sector & 52 & $21.7 \%$ \\
\hline Business & 36 & $15 \%$ \\
\hline Student & 114 & $47.5 \%$ \\
\hline Total & 240 & $100 \%$ \\
\hline
\end{tabular}

The table of internet buying experience shows that 143 respondents had engaged in online shopping only once and 97 respondents had never engaged in online shopping, which makes it a total of 240 respondents (57.4\%) who have zero or limited experience of online shopping. Gender table shows that $70 \%$ of the respondents are male and $30 \%$ of them are female. Age table reveals that the majority of respondents $(56.7 \%)$ fall in the age group 18-29 years followed by respondents in the age group 30-39 years which makes $25 \%$ of the total sample. Around $11 \%$ of the respondents are below 18 years and only $7.5 \%$ of them are older than 40 years.

The majority of the respondents are under-graduates $(53.3 \%)$ followed by graduates (26.7\%). $12.5 \%$ of the respondents have Masters or higher-level education and only $7.5 \%$ of them are an intermediate pass. Employment table reveals that most of the respondents are students (47.5\%) followed by private-sector employees (21.7\%), government employees (15.8\%) and businessmen (15\%).

The survey asked consumers about 13 observed impediments which influence their internet purchase behavior. These impediments are selected after a detailed study of the literature review. The statements are ranked on the basis of the mean score. Higher mean score corresponds to higher rank which means higher hurdle. The consumer replies are examined and shown in Table 6:

The barrier 'There are security and privacy risks in online shopping' got the highest rank with a mean of 4.12. The consumers believe that internet purchasing exposes them to a number of safety and protection threats like stolen identity, password breach and stealing of credit/debit card information. This may be because of their limited knowledge of the use of anti-virus and safe browsing options.

The second statement with the highest response (4.03) is 'English language is an impediment to me while doing internet purchasing. Most respondents believe that inadequate command over the English language acts as an impediment to browse international websites like amazon and e-bay which may influence their purchase intention. Although there is a significant increase in Saudi consumers having a good command of the English language, the majority of them don't consider themselves fluent enough to shop online because of difficulty in understanding product specifications and other details.

The third barrier with the highest response (4.0) is ' I trust tangible goods'. The majority of consumers believe that the failure to see and examine the tangible good impedes their internet purchasing conduct. As a result of cultural differences, Saudi consumers are cautious of using western practices and they still believe in traditional methods of shopping.

The factor at a fourth rank (3.95) is 'I don't use a credit card'. Most of the respondents don't favor using a credit card for shopping because of security issues. They are afraid of online scams and credit card frauds. 
Table 6. Perceived barriers which affect consumers online shopping behavior

\begin{tabular}{|c|c|c|c|c|c|c|c|c|}
\hline S. no & Factors affecting perception of consumers & SA & A & NAND & D & SD & Mean & Rank \\
\hline 1. & Online shopping has high shipping cost & 56 & 84 & 30 & 40 & 30 & 3.40 & 7 \\
\hline 2. & $\begin{array}{l}\text { All the online products are easily available in local } \\
\text { market. }\end{array}$ & 64 & 56 & 40 & 28 & 52 & 3.22 & 10 \\
\hline 3. & $\begin{array}{l}\text { Me or my friend/family had a bad experience with } \\
\text { online shopping in the past }\end{array}$ & 44 & 52 & 44 & 54 & 46 & 2.97 & 12 \\
\hline 4. & $\begin{array}{l}\text { There are security and privacy risks in online } \\
\text { shopping }\end{array}$ & 116 & 74 & 22 & 20 & 8 & 4.12 & 1 \\
\hline 5. & There is problem of delivery to accurate location. & 76 & 67 & 37 & 34 & 26 & 3.55 & 6 \\
\hline 6. & Online shopping is expensive & 34 & 72 & 34 & 56 & 44 & 2.98 & 11 \\
\hline 7. & I don't use a credit card & 100 & 76 & 24 & 32 & 8 & 3.95 & 4 \\
\hline 8. & I trust only tangible products & 116 & 72 & 4 & 32 & 16 & 4.0 & 3 \\
\hline 9. & Product delivery takes a long time & 82 & 42 & 28 & 54 & 34 & 3.35 & 8 \\
\hline 10. & After-sales service is poor in online shopping & 66 & 56 & 38 & 44 & 36 & 3.3 & 9 \\
\hline 11. & Online products are of poor quality & 28 & 44 & 32 & 80 & 56 & 2.62 & 13 \\
\hline 12. & There is issue of distrust and credibility & 90 & 60 & 20 & 44 & 26 & 3.60 & 5 \\
\hline 13. & $\begin{array}{l}\text { English language is an impediment to me while } \\
\text { doing internet purchasing }\end{array}$ & 172 & 4 & 0 & 28 & 36 & 4.03 & 2 \\
\hline
\end{tabular}

The next barrier with the highest response (3.60) is 'There is an issue of distrust and credibility' which implies that respondents are uneasy about online shopping activities. The respondents give more importance to interaction with the seller with whom they have good relations. Therefore, they like to visit the shop for purchasing products. They also believe they can negotiate product prices and buy on credit from these sellers.

The other impediments to internet purchasing with high agreement response (greater than 3.0) in decreasing order are a problem of delivery to accurate location, high shipping cost, long time in product delivery, poor aftersales service and accessibility of web-based goods in local stores. Delivery to exact location is a major barrier to online shopping in Saudi Arabia because the street and home addresses are not properly defined. Due to this, the shipment arrives at some landmark near the residence of a customer from where the customer picks it. If the customer is not at home, this further delays product delivery. Consumers also perceive the online product to be expensive because of high delivery charges, and complicated post-sales service. Therefore, they don't want to purchase products online if they are already available in the local market.

Some customers agreed that they or their friends/ family had a bad experience with online shopping in the past which influenced their online purchase behavior. This implies that word-of-mouth may have a drastic impact on consumer perception regarding online shopping. Some respondents considered online products to be of poor quality may be because of past experience or word-of-mouth.

We use the chi-square test to decide whether the frequency distributions of one or more categorical variables are statistically independent. In this study, we use the chi-square test to examine if buyers' feelings about impediments to internet purchasing are independent of their education, age and shopping experience. The value of significance ( $\mathrm{p}$-value) helps us to decide whether to reject the null hypothesis or not. If the p-value is less than one, we reject the Null hypothesis and vice versa.

H01: The impediment of security and privacy risks in internet purchasing is independent of the education level of respondents.

As shown in Table 7, the p-value (Asymp. Sig-2 sided) is more than 0.05 , hence we fail to reject the null hypothesis $\mathrm{H} 01$ at 5\% level of significance. So the impediment of security and privacy risks in online shopping does not depend on the education level of respondents. It means that all the respondents, irrespective of their education agree that there are security and privacy risks associated with online shopping. This may be because of the fact 
Table 7. Barrier of security and privacy risks

\begin{tabular}{|c|c|c|c|c|c|c|c|c|}
\hline S.no & Education level & SA & A & NAND & $\mathrm{D}$ & SD & Total & Chi-square value \\
\hline 1 & Intermediate & 8 & 4 & 3 & 2 & 1 & 18 & \multirow{4}{*}{$\begin{array}{c}\text { Chi-square value }=17.721 \\
\text { Sig. }(p \text {-value })=.1244^{*}\end{array}$} \\
\hline 2 & Under-graduate & 66 & 38 & 8 & 12 & 4 & 128 & \\
\hline 3 & Graduate & 30 & 22 & 7 & 3 & 2 & 64 & \\
\hline 4 & Masters and above & 12 & 10 & 4 & 3 & 1 & 30 & \\
\hline & Total & 116 & 74 & 22 & 20 & 8 & 240 & \\
\hline
\end{tabular}

*Statistically significant at $p<.05$ level.

Table 8. Barrier of trusting tangible products

\begin{tabular}{|c|c|c|c|c|c|c|c|c|}
\hline S. no & Age & SA & $\mathrm{A}$ & NAND & $\mathrm{D}$ & SD & Total & Chi-square value \\
\hline 1 & Less than 18 years & 12 & 8 & 0 & 5 & 1 & 26 & \multirow{4}{*}{$\begin{array}{c}\text { Chi-square value }=20.841 \\
\text { Sig. }(p \text {-value })=.0527^{\star}\end{array}$} \\
\hline 2 & $18-29$ years & 72 & 40 & 0 & 10 & 14 & 136 & \\
\hline 3 & $30-39$ years & 28 & 18 & 1 & 12 & 1 & 60 & \\
\hline \multirow[t]{2}{*}{4} & 40 years or more & 4 & 6 & 3 & 5 & 0 & 18 & \\
\hline & Total & 116 & 72 & 4 & 32 & 16 & 240 & \\
\hline
\end{tabular}

*Statistically significant at $p<.05$ level.

that the online shopping experience of the respondents is limited to only one time or never. Moreover, it is possible that security and privacy risks are a major barrier to online shopping among respondents.

H02: The barrier of trusting only tangible products is independent of the age of respondents.

As shown in Table 8, the p-value (Asymp. Sig-2 sided) is more than 0.05 , hence we fail to reject the null hypothesis $\mathrm{H} 02$ at $5 \%$ level of significance.

It implies that all age groups uniformly trust tangible products as compared to online products. Again, this revelation may be attributed to the special set of respondents chosen for the study, i.e. online shopping experience limited to only one time or never. This characteristic of trusting tangible products may also act as a major barrier to online shopping.

H03: The hurdle of mistrust and trustworthiness is independent of the online shopping experience of buyers.

As shown in Table 9, the p-value (Asymp. Sig-2 sided) is less than 0.05 , hence the null hypothesis $\mathrm{H} 03$ is rejected at $5 \%$ level of significance.

So the barrier of distrust and credibility is dependent on the online shopping experience of customers. It is found that the respondents who have never engaged in online shopping associate more distrust and credibility issues with online shopping as compared to those who have engaged in online shopping only once. It is possible that the respondents who engaged at least once in online shopping perceived it as trusted and credible.

\section{Discussion, Recommendation and Implications}

It was found that the barrier of security and privacy risks in online shopping is independent of the study level of consumers. The impediment of believing in tangible products is independent of the age of consumers. Moreover, the barrier of distrust and credibility is dependent on the online shopping experience of customers.

The barrier of security and privacy risks in online shopping has scored the highest response. The second factor with the highest response is the English language barrier. The third barrier with the highest response is trusting tangible products. The fourth factor with the highest response is not using a credit card. The fifth barrier with the highest response is the issue of distrust and credibility.

There are some other concerns that must be addressed regarding hurdles to internet purchase acceptance in Saudi Arabia. Saudi postal address system in Saudi Arabia needs to be well developed to find the exact location of the customer. As of now, most of the orders are delivered to offices or the courier service company from where 
Table 9. Barrier of distrust and credibility

\begin{tabular}{|c|c|c|c|c|c|c|c|c|}
\hline S.no & Experience & SA & A & NAND & $\mathrm{D}$ & SD & Total & Chi-square value \\
\hline 1 & Engaged only once & 28 & 37 & 16 & 39 & 23 & 143 & \multirow{2}{*}{$\begin{array}{c}\text { Chi-square value }=34.128 \\
\text { Sig. }(p \text {-value })=.00001^{\star}\end{array}$} \\
\hline 2 & $\begin{array}{l}\text { Never engaged in } \\
\text { online shopping }\end{array}$ & 62 & 23 & 4 & 5 & 3 & 97 & \\
\hline & Total & 90 & 60 & 20 & 44 & 26 & 240 & \\
\hline
\end{tabular}

${ }^{\star}$ Statistically significant at $\mathrm{p}<.05$ level.

customers collect their package. Many consumers prefer to make cash payments as they consider it the best way to manage their expenditure. The credibility of websites used for internet purchase is often doubtful, due to fragile regulatory framework. $\underline{\underline{5}}$

The following measures are recommended to overcome the impediments to electronic trade in Saudi Arabia:

1. The Government should develop more laws, rules, regulations and policies for e-commerce inside the Kingdom.

2. The government should start a website that acts as a mediator between traders and buyers.

3. There should be awareness drives to educate buyers about the benefits of internet shopping.

4. Banks should offer extra options to make the payment process easy for customers. Banks should offer credit/debit cards in order to encourage them to purchase through the internet.

5. Internet traders should develop easy-to-use internet sites to motivate consumers with beginner-level computer knowledge to try the online market. Both Arabic and English languages should be available in the interface of these websites.

6. The majority of the respondents use their smartphones to access the Internet. This is a chance for online retailers to entice consumers to their website through smartphones. As mobile commerce is increasing in Saudi Arabia, retailers should develop a website that is easy-to-use and compatible with smartphone screens.

7. As new online consumers perceive financial risk, internet traders in Saudi Arabia need to ensure the safety of consumers' financial details. The websites must require a password from the consumer's bank before payment is completed. This password should be sent to the consumer's phone and entered online.

8. Retailers should make their Terms and Conditions, Privacy Policy, Returns Policy and their contact details available on their website.
9. The payment page should also have a padlock symbol visible to indicate that the website is secure.

10. Online retailers could provide money-back guarantees to reassure consumers of the safety of making purchases through the internet.

11. Internet traders need to protect their reputation as new online consumers are more affected by word-of-mouth.

The implications of this research are that it offers the government and businesses with valuable insights about buyer's perceptions regarding impediments to internet purchasing acceptance. The government and businesses can consider and implement the suggestions of this study to work together and take measures to overcome the impediments identified in this study such as security, privacy, credibility, delivery, language and customer support concerns of buyers. This study is particularly useful for International firms that are planning to establish their base in the Kingdom of Saudi Arabia. Such international firms will better understand the attitude and perception of Saudi consumers regarding internet buying; and they can benefit from the insights provided by this study to establish their presence and increase sales in the Kingdom.

\section{Conclusion}

This study presents results related to barriers to internet shopping acceptance in Saudi Arabia from the viewpoint of a consumer. The study concludes that consumers believe that internet shopping makes them vulnerable to a number of security threats like credit card frauds and identity theft. Saudi citizens prefer limited social interaction and desire home delivery of their orders. The majority of respondents believe that poor English comprehension acts as an impediment towards their purchase intention. Saudi consumers were found to prefer traditional methods of shopping. The other impediments 
to internet purchasing were a problem of delivery to accurate location, high shipping cost, a long time in product delivery, poor after-sales service and accessibility of web-based goods in local stores. Word-of-mouth plays a vital role in consumer perception regarding online shopping. It is found that the respondents who have zero or limited experience in online shopping associate more security, privacy, and credibility and delivery concerns with online shopping. This makes it important for governments and businesses to gain their trust and remove their pre-conceived notions regarding online shopping.

However, the future holds bright prospects for internet shopping acceptance in Saudi Arabia. Saudi Arabia has a small number of chain stores like Panda, Lulu, Jarir, etc. as compared to its vast geographical area. These stores should utilize this huge potential market by providing their products through the internet.

Like other studies, this study is also not free from constraints. One of the constraints of this study is that the respondents are limited to participants from Hail, Qassim and Riyadh region in Saudi Arabia. A broad conclusion can be formed by collecting data in a larger survey from respondents' across the country. There is a need to increase the knowledge base regarding internet purchase acceptance in Saudi Arabia from both consumers' and retailers' perspectives through future research.

\section{References}

1. Al-Salamin H, Al-Hammad A. Attitude of Saudi consumers towards online shopping with special reference to Al-Hassa region (KSA). J WEI Bus Econ. 2014;3(3):39-56.

2. E commerce in Saudi Arabia. [cited 2017]. https://www. citc.gov.sa/en/reportsandstudies/Reports/Documents/ CITC_ECOMMERCE_2017_ENGLISH.PDF.

3. Almousa M. Barriers to E-commerce adoption: consumers perspectives from developing countries. iBusiness. 2013;5(2):65-71.
4. Rehman A, Elahi, Y. An empirical study of perception of women consumers towards internet marketing in Lucknow region. In: Gender equality development and women empowerment. 2014. P. 46.

5. Sohail MS. Factors impeding online shopping: an Arab world perspective. Eur Online J Nat Soc Sci. 2014;3(4):972-82.

6. Alqahtani A, Goodwin R, Vries D. Structural equation modelling of the factors influencing the adoption of e-commerce in Saudi Arabia. J Electron Com Org. 2019;17(4):21.

7. Rehman A. An empirical study of perception of consumers towards online shopping in Kingdom of Saudi Arabia. Int J Retail Rural Bus Perspect. 2016;5(2):78-86.

8. AlGhamdi R, Drew S, Alfaraj O. Issues influencing Saudi customers' decisions to purchase from online retailers in the KSA: a qualitative analysis. Eur J Sci Res. 2011;55(4):580.

9. Al-Somali SA, Gholami R, Clegg B. An investigation into the acceptance of online banking in Saudi Arabia. Technovation. 2009;29(2):130-141.

10. Siddiqui $H$. Investigation of intention to use e-commerce in the Arab countries: a comparison of self-efficacy, usefulness, culture, gender, and socioeconomic status in Saudi Arabia and the United Arab Emirates [PhD. Thesis]. Orlando: Nova Southeastern University; 2008.

11. AlGhamdi R, Drew S and Al-Ghaith W. Factors Influencing e-commerce adoption by retailers in Saudi Arabia: a qualitative analysis. Electron J Inf Syst Dev Countr. 2012;47(7):1-23.

12. Alsharif M. E-Commerce adoption factors and their implications for e-commerce business strategy in Saudi Arabia [Master Thesis]. London: Simon Fraser University; 2011.

13. Aladwani AM. Key internet characteristics and e-commerce issues in Arab countries. Inf Manag. 2003;16(1):9-20.

14. Al-Solbi A, Mayhew PJ. Measuring e-readiness assessment in Saudi organizations: preliminary results from a survey study. In: The proceedings of the 1st European conference on mobile government; 2005. P. 1-10.

15. Saudi post. [cited 2019 Oct 09]. https://en.wikipedia.org/ wiki/Saudi_Post. 